\title{
Effect of temperature on the retention of amino acids and carbohydrates in high-performance anion-exchange chromatography
}

\author{
Hong $\mathrm{Yu}^{\mathrm{a}}{ }^{\mathrm{b}}$, Shi-Fen Mou ${ }^{\mathrm{b}, *}$ \\ a Department of Chemistry, Harbin Normal University, Harbin 150080, China \\ ${ }^{\mathrm{b}}$ Research Center for Eco-Environmental Sciences, Academia Sinica, P.O. Box 2871, Beijing 100085, China
}

Available online 10 January 2006

\begin{abstract}
Effect of temperature on the retention of amino acids and carbohydrates in high-performance anion-exchange chromatography (HPAEC) was investigated. Amino acids retention exhibited both exothermic and endothermic behavior. Significant selectivity variations of some weakly retained amino acids were achieved through changing temperature. However, temperature was almost ineffective at changing the selectivity of strongly retained amino acids. Sugars retention exhibited only exothermic behavior. However, individual carbohydrates showed different relative changes in retention time with increased temperature. There is the general regularity, which is the variation of retention time increases as the sequence of monosaccharide, disaccharide, trisaccharide and tetrasaccharide when the column temperature is increased. Selectivity changes of carbohydrates, including elution order reversal, were also achieved by varying temperature. Temperature was effective at changing the selectivity of between amino acids and carbohydrates. In achieving optimal separation of amino acids and carbohydrates, temperature is a valuable tool.
\end{abstract}

(C) 2005 Elsevier B.V. All rights reserved.

Keywords: Amino acids; Carbohydrates; Temperature; Retention; Anion exchange

\section{Introduction}

In the last decade, high-performance anion-exchange chromatography (HPAEC) with pulsed amperometric detection (PAD) has proven to be a useful tool for carbohydrate analysis [1-3]. In the recently, Clarke et al. [4] developed an integrated amperometry waveform (IPAD) for the direct, sensitive detection of amino acids and amino sugars following anion-exchange chromatography. Amino acids and carbohydrates can be separated and detected by high-performance anion-exchange chromatography with integrated amperometry detection [5-7]. Factors affecting retention times and selectivity of amino acids and carbohydrates in HPAEC mainly include stationary phase type, mobile phase, flow rate and column temperature. The attractive features of using temperature for optimizing a chromatographic method are: it is experimentally easy to implement; it is applicable to both neutral and charged analytes; and it is easy to model. In recent years temperature has become an increasingly popular parameter in high-performance liquid chromatog-

\footnotetext{
* Corresponding author. Tel.: +86 1062849182; fax: +86 1062849239.

E-mail address: shifenm@mail.rcees.ac.cn (S.-F. Mou).
}

raphy method development, particularly for reversed-phase liquid chromatography [8-18]. However, temperature has been a rarely exploited variable in ion-exchange chromatography. Baba et al. $[19,20]$ investigated the effect of column temperature on high-performance anion-exchange chromatographic behaviour of inorganic polyphosphates. Fortier and Fritz [21] studied the influence of temperature on single column ion chromatography of metal ions. Smith et al. [22] studied the temperature programming in macrocycle-based ion chromatography. Lee and Hoffman [23] studied the effect of temperature on the retention of simple organic compounds in ion exchange HPLC. Landberg et al. [24] investigated the temperature effects in high-performance anion-exchange chromatography of oligosaccharides. Kolpachnikova et al. [25] investigated the effect of temperature on retention of alkali and alkaline earth metal ions on some aminocarboxylic acid functionalised silica based ion exchangers. Busch and Seubert [26] investigated the influence of column temperature on the ion chromatographic separation of aluminum species. Panagiotopoulos et al. investigate the effect of temperature on the separation of monosaccharides in high-performance anion-exchange chromatography [27]. Hatsis and Lucy [28-32] studied the effect of temperature on retention and selectivity in ion chromatography of inorganic 
anions and cations. Barron et al. [33] investigate the use of temperature programming to improve resolution of inorganic anions, haloacetic acids and oxyhalides in drinking water by suppressed ion chromatography.

In our previous publications we reported the determination of amino acids and carbohydrates by HPAEC-IPAD [6,7,34]. This paper presents temperature effects in high-performance anionexchange chromatography of amino acids and carbohydrates. Temperature can be used to change the selectivity and separation of amino acids and carbohydrates.

\section{Experimental}

\subsection{Reagents}

Standard amino acids, fucose, arabinose, glucose, fructose, ribose, sucrose, lactose, raffinose, maltose, isomaltose and sodium azide were purchased from Sigma-Aldrich (St. Louis, MO, USA); maltotriose, isomaltotriose, panose, maltotetraose and glucuronic acid were from Tokyo Kasei Kogyo (Tokyo, Japan), and were used as received. The single component stock solutions $(\sim 0.5 \mathrm{mM})$ of amino acids and carbohydrates were prepared in $18 \mathrm{M} \Omega$ water containing $20 \mathrm{mg} / \mathrm{l}$ sodium azide to prevent microbial growth. The injected standard mixture solutions of amino acids and carbohydrates were made by diluting corresponding aliquots of the single component stock solutions of amino acids and sugars with an aqueous diluent containing $20 \mathrm{mg} / \mathrm{l}$ sodium azide. Eighteen megaOhm water, sodium hydroxide (Beijing Chemical Factory, Beijing, China), and anhydrous sodium acetate (Dionex, Sunnyvale, CA, USA) were used to prepare the gradient mobile phase. Molbile phase I was $18 \mathrm{M} \Omega$ water vacuum-filtered through a $0.2 \mu \mathrm{m}$ nylon filter. Molbile phase II, a $250 \mathrm{mM}$ sodium hydroxide solution, was prepared by diluting an aliquot of $50 \%$ sodium hydroxide, which was prepared by dissolving solid sodium hydroxide in $18 \mathrm{M} \Omega$ water. The resulting 50\% solution was kept undisturbed for $24 \mathrm{~h}$ to allow the sodium carbonate to settle at the bottom prior to the last dilution step to $250 \mathrm{mM}$. Mobile phase III, a $1 \mathrm{mM}$ sodium acetate solution, was prepared by dissolving an aliquot of anhydrous sodium acetate in $18 \mathrm{M} \Omega$ water and filtering the solution through a $0.2 \mu \mathrm{m}$ nylon filter. All three mobile phases were kept under nitrogen to prevent the accumulation of atmospheric carbon dioxide.

\subsection{Instrumentation}

All experiments were performed using a DX-600 ion chromatograph (Dionex). The ion chromatographic system consisted of a GS50 gradient pump with on-line degas, an AS50 autosampler, an AS50 thermal compartment containing a set of chromatographic columns, and an ED50 electrochemical detector equipped with a thin-layer type amperometric cell. The cell consisted of a gold electrode, a combination reference electrode of glass and $\mathrm{Ag} / \mathrm{AgCl}(3 \mathrm{M} \mathrm{KCl})$ and titanium counter electrode consisting of the cell body. Separation was carried out using the AminoPac PA 10 column set consisting of a guard column $(50 \mathrm{~mm} \times 2 \mathrm{~mm}$ I.D. $)$ and an analytical column
Table 1

Detection waveform for amino acids and carbohydrates

\begin{tabular}{rll}
\hline Time $(\mathrm{ms})$ & $\begin{array}{l}\text { Potential }(\mathrm{V}) \text { vs. glass- } \mathrm{Ag} / \mathrm{AgCl} \\
(3 \mathrm{M} \mathrm{KCl})\end{array}$ & Current integration \\
\hline 0 & 0.13 & \\
40 & 0.13 & \\
50 & 0.33 & \\
210 & 0.33 & \\
220 & 0.60 & \\
460 & 0.60 & \\
470 & 0.33 & \\
560 & 0.33 & \\
570 & -1.67 & \\
580 & -1.67 & \\
590 & 0.93 & \\
600 & 0.13 & \\
\hline
\end{tabular}

$(250 \mathrm{~mm} \times 2 \mathrm{~mm}$ I.D. $)$. Both columns were packed with an identical microporous, polymeric anion exchange material. The total ion-exchange capacity of the analytical column was $60 \mu$ equiv. The columns and the electrochemical detection cell were placed inside the AS50 thermal compartment for their temperature control. The chromatographic system control, data acquisition and data analysis were performed using the PeakNet 6.3 Software. The integrated amperometry detection waveform is presented in Table 1. Flow-rate was $0.25 \mathrm{ml} / \mathrm{min}$. The sample injection volume was $25 \mu 1$.

\section{Results and discussion}

In anion-exchange chromatography, the exchange reaction for an analyte ion, A, and eluent ion, E, can be written as:

$\mathrm{R}-\mathrm{E}+\mathrm{A} \rightleftharpoons \mathrm{R}-\mathrm{A}+\mathrm{E}$

where $\mathrm{R}$ represent the resin. The exchange reaction can be either exothermic or endothermic, depending on the ions involved. The ion-exchange equilibrium can thus be shifted in either direction as the temperature is increased, resulting in a change in the capacity factor, $k^{\prime}$, for the analyte ion.

To show the relationship between retention value and temperature, Van't Hoff plots were constructed. The relationship between capacity factor, $k^{\prime}$, and system temperature (Kelvin), $T$, is mathematically represented by:

$\ln k^{\prime}=\frac{-\Delta H^{\circ}}{R T}+\frac{\Delta S^{\circ}}{R}+\ln \phi$

where $\Delta H^{\circ}$ is the enthalpy change for the exchange reaction, $\Delta S^{\circ}$ is the corresponding change in standard entropy, $R$ is the universal gas constant, and $\phi$ is the column phase-ratio, a characteristic constant for a given column. When enthalpy and entropy changes are temperature invariant, plots of $\ln k$ versus $1 / T$ (Van't Hoff plots) are linear and should have a slope equal to $-\Delta H^{\circ} / R$.

\subsection{Effect of temperature on the retention of amino acids}

Sodium hydroxide and sodium acetate were used as eluent for separation of amino acids and carbohydrates. Solution of 


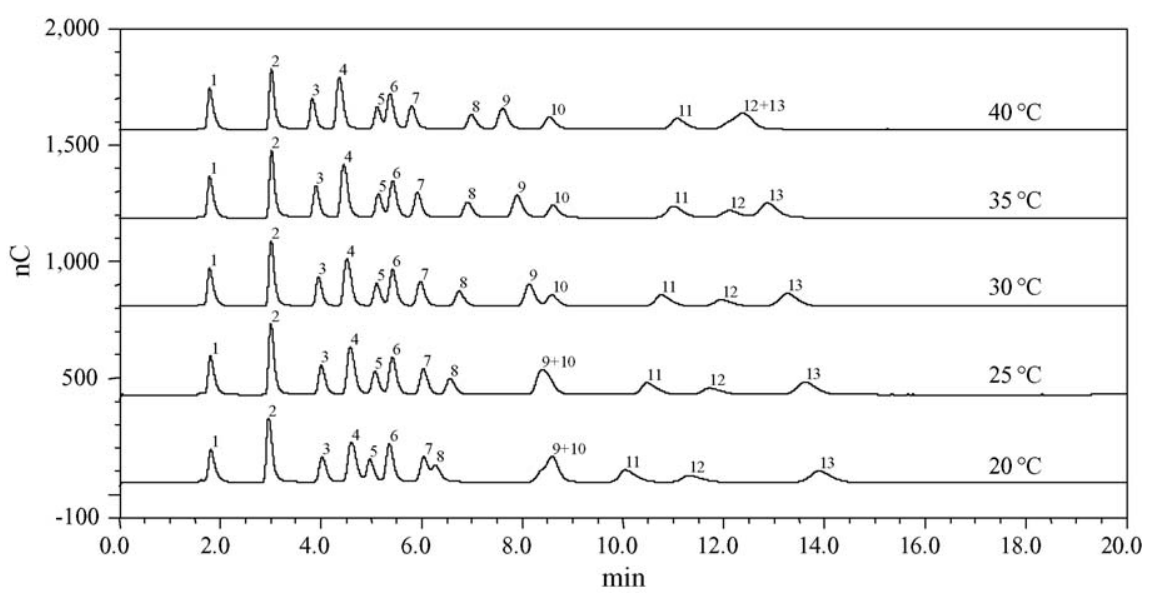

Fig. 1. Chromatograms of weakly retained amino acids obtained with constant eluent concentration of $80 \mathrm{mM}$ sodium hydroxide at various column temperatures from 20 to $40^{\circ} \mathrm{C}$. Peak: (1) arginine; (2) lysine; (3) glutamine; (4) asparagine; (5) alanine; (6) threonine; (7) glycine; (8) valine; (9) serine; (10) proline; (11) isoleucine; (12) leucine and (13) methionine.

sodium hydroxide supplies a basic condition for separation and detection of amino acids and carbohydrates. Sodium hydroxide was used elute weakly retained amino acids and carbohydrates. Sodium acetate was used to elute strongly retained amino acids and carbohydrates.

Fig. 1 shows chromatograms for the mixture of weakly retained amino acids obtained at various column temperatures from 20 to $40^{\circ} \mathrm{C}$ with constant eluent concentration of $80 \mathrm{mM}$ sodium hydroxide. The marked temperature effect on the chromatographic behavior of some solutes is observed. The retention times for valine, isoleucine and leucine are obviously increased with increasing temperature. However, the retention times for serine and methionine are obviously decreased with increasing temperature. For other amino acids, the retention time changes with varying column temperature are not obvious. The reason for above phenomenon could be that the retention of amino acids in anion-exchange chromatography exhibited an endothermic process (retention to be increased with increasing temperature) or exothermic process (retention to be decreased with increasing temperature). That is the exchange reaction exhibited either endothermic or exothermic, depending on the amino acids involved. Thus, significant selectivity changes of some weakly retained amino acids, which are eluted with sodium hydroxide eluent, can be achieved by changing the column temperature. Regression parameters of the Van't Hoff plots for weakly retained amino acids are presented in Table 2. The slopes of the Van't Hoff plots are both negative and positive. The negative slopes indicate that the retention of amino acids is an endothermic process. The positive slopes indicate that the retention of amino acids is an exothermic process. The separation between two closely eluted amino acids can be improved by changing column temperature. For example, serine and proline are the overlapping peak at $25^{\circ} \mathrm{C}$, whose separation is not success by changing eluent concentration, but both are completely separated at $35^{\circ} \mathrm{C}$, whose resolution is equal to 1.84 . Another example, leucine and methionine are the overlapping peak at $40^{\circ} \mathrm{C}$, but the good separation between them is obtained at $35^{\circ} \mathrm{C}$, whose resolution is 1.42 .
Fig. 2 shows chromatograms for the mixture of strongly retained amino acids obtained at various column temperatures from 25 to $40^{\circ} \mathrm{C}$ with constant eluent concentration of $200 \mathrm{mM}$ sodium acetate and $60 \mathrm{mM}$ sodium hydroxide. The retention time is basically invariant when the temperature increases. The marked temperature effect on the chromatographic behavior of each strongly retained amino acid is not observed.

\subsection{Effect of temperature on the retention of carbohydrates}

Fig. 3 shows chromatograms for the mixture of weakly retained carbohydrates obtained with constant eluent concentration of $80 \mathrm{mM}$ sodium hydroxide at various column temperatures from 20 to $40^{\circ} \mathrm{C}$. The retention times of carbohydrates are decreased with increasing temperature and this effect is more pronounced for disaccharides and trisaccharides. The result indicates that the retention of weakly retained carbohydrates in anion-exchange chromatography is an exothermic process (retention to be decreased with increasing temperature). That is the exchange reactions of weakly retained carbohydrates are exothermic. However, the effect of temperature for each carbo-

Table 2

Linear regression data for plot of $\ln k^{\prime}$ vs. $1 / T\left(\times 10^{3} \mathrm{~K}^{-1}\right)$ of weakly retained amino acids with $80 \mathrm{mM}$ sodium hydroxide eluent

\begin{tabular}{lccl}
\hline Analyte & Slope $=-\Delta H^{\circ} / R$ & Intercept $=\Delta S / R+\ln \phi$ & $\begin{array}{l}\text { Correlation } \\
\text { coefficient }\left(r^{2}\right)\end{array}$ \\
\hline Glutamine & 0.3107 & -0.6452 & 0.9614 \\
Asparagine & 0.3207 & -0.464 & 0.9681 \\
Alanine & -0.2141 & 1.4825 & 0.9092 \\
Threonine & -0.0757 & 1.114 & 0.9061 \\
Glycine & 0.1944 & 0.3585 & 0.9174 \\
Valine & -0.6513 & 3.3043 & 0.9612 \\
Serine & 0.6222 & -0.6492 & 0.9907 \\
Proline & -0.2031 & 2.1329 & 0.9157 \\
Isoleucine & -0.5418 & 3.5221 & 0.9583 \\
Leucine & -0.4887 & 3.4744 & 0.9738 \\
Methionine & 0.5475 & 0.1737 & 0.9803 \\
\hline
\end{tabular}




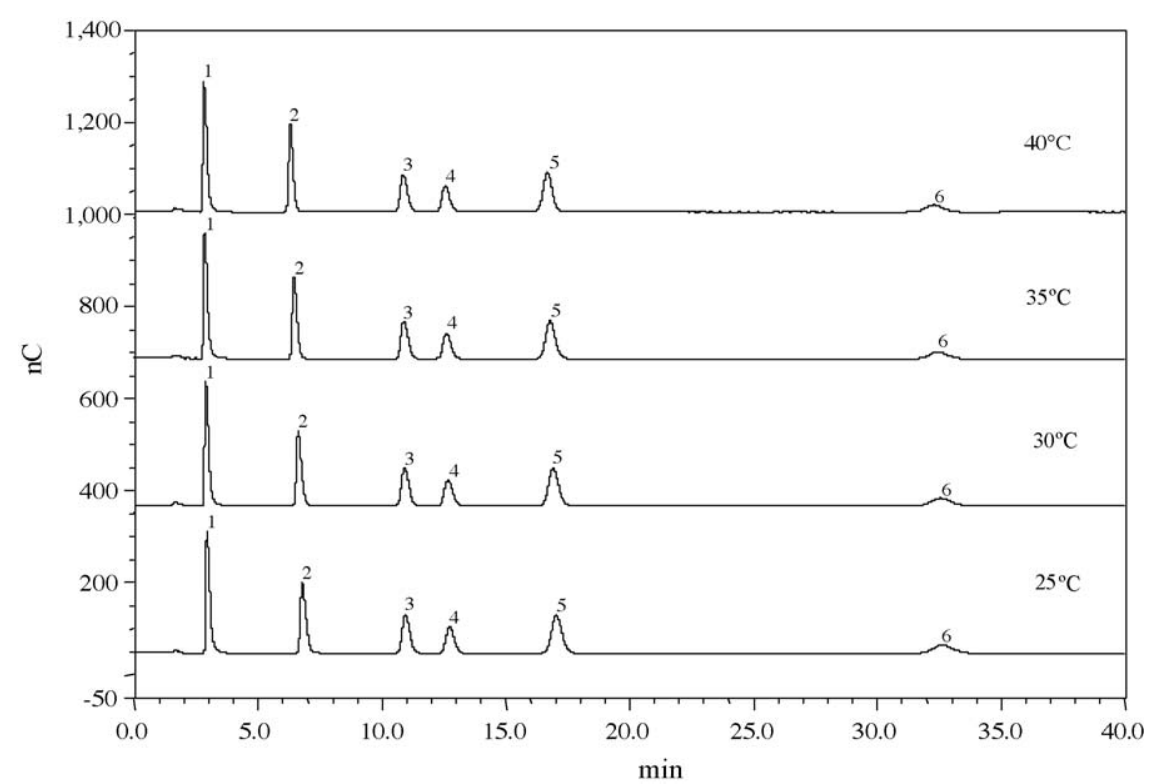

Fig. 2. Chromatograms of strongly retained amino acids obtained with constant eluent concentration of $200 \mathrm{mM}$ sodium acetate and $60 \mathrm{mM}$ sodium hydroxide at various column temperatures from 25 to $40^{\circ} \mathrm{C}$. Peak: (1) histidine; (2) phenylalanine; (3) glutamic acid; (4) aspartic acid; (5) cystine and (6) tyrosine.

hydrate is different. That is the variation of retention time for each carbohydrate is different with the change of temperature. Generally, the variation of retention time for disaccharides is great than that for monosaccharide. Thus, selectivity changes of weakly retained carbohydrates can be achieved by changing the column temperature. Regression parameters of the Van't Hoff plots for weakly retained carbohydrates are presented in Table 3. The slopes of the Van't Hoff plots are positive. The positive slopes indicate that the retention of weakly retained carbohydrate is an exothermic process. The separation between two closely eluted carbohydrates can be improved by changing column temperature. For example, sucrose and lactose are the overlapping peak at $35^{\circ} \mathrm{C}$, but both are completely separated bellow $30^{\circ} \mathrm{C}$.

Fig. 4 shows chromatograms for the mixture of strongly retained carbohydrates obtained at various column temperatures from 20 to $40^{\circ} \mathrm{C}$ at constant eluent concentration $(50 \mathrm{mM}$ sodium acetate and $60 \mathrm{mM}$ sodium hydroxide). The marked temperature effect on the chromatographic behavior of each solute is observed. The retention time of strongly retained carbohy-

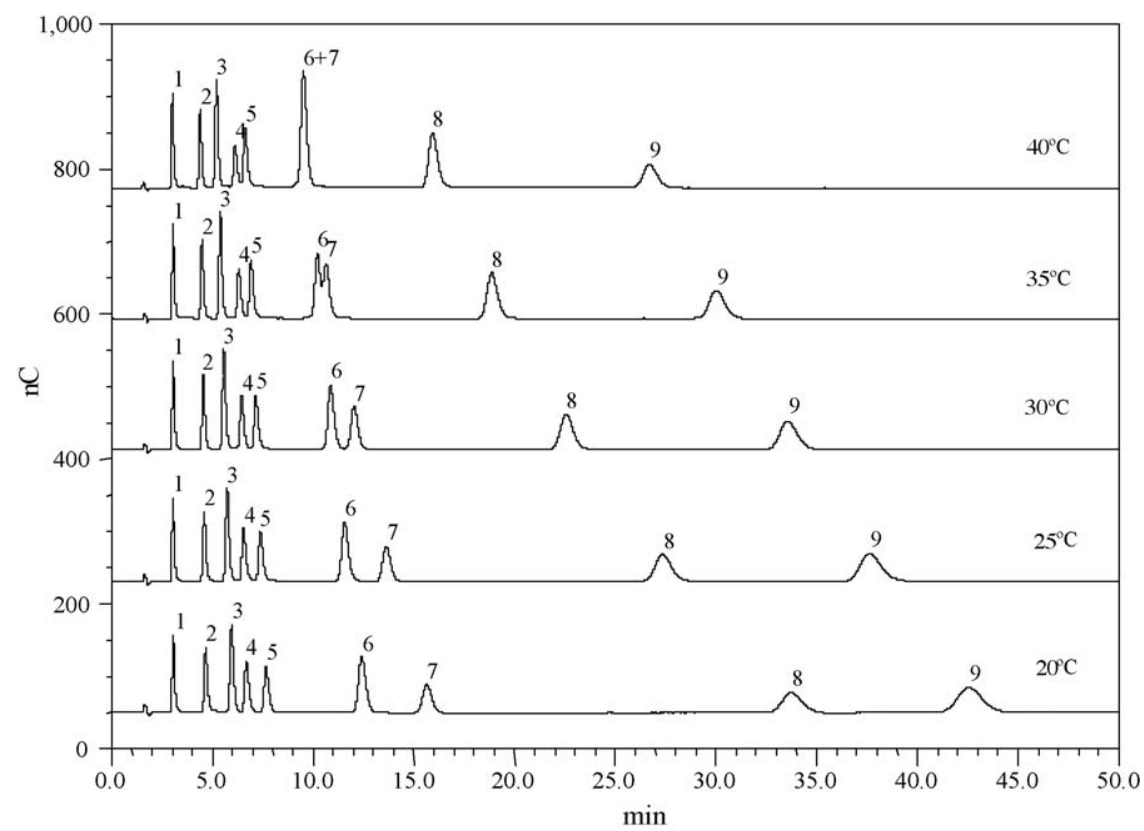

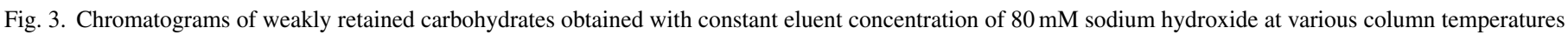
from 20 to $40^{\circ}$ C. Peak: (1) fucose; (2) arabinose; (3) glucose; (4) fructose; (5) ribose; (6) sucrose; (7) lactose; (8) raffinose and (9) maltose. 


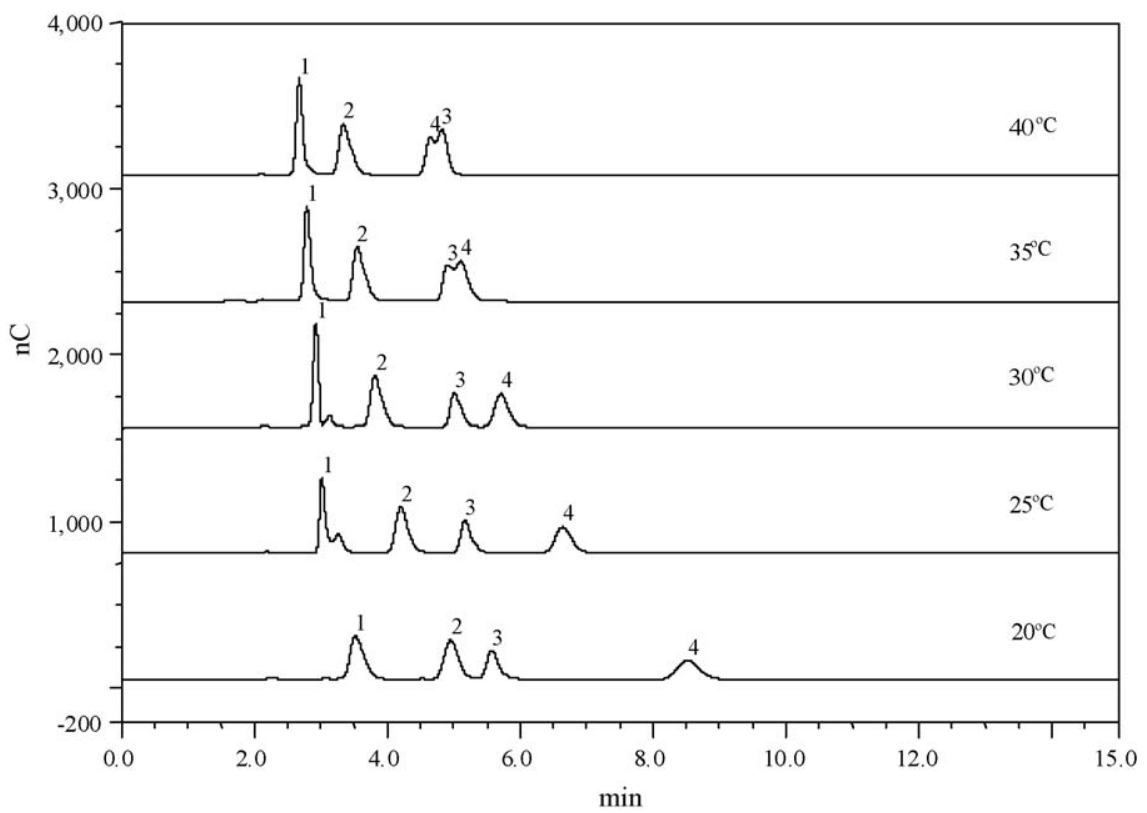

Fig. 4. Chromatograms of strongly retained carbohydrates obtained with constant eluent concentration of $50 \mathrm{mM}$ sodium acetate and $60 \mathrm{mM}$ sodium hydroxide at various column temperatures from 20 to $40^{\circ} \mathrm{C}$. Peak: (1) panose; (2) maltotriose; (3) glucuronic acid and (4) maltotetraose.

Table 3

Linear regression data for plot of $\ln k^{\prime}$ vs. $1 / T\left(\times 10^{3} \mathrm{~K}^{-1}\right)$ of weakly retained carbohydrates with $80 \mathrm{mM}$ sodium hydroxide eluent

\begin{tabular}{llll}
\hline Analyte & Slope $=-\Delta H^{\circ} / R$ & Intercept $=\Delta S / R+\ln \phi$ & $\begin{array}{l}\text { Correlation } \\
\text { coefficient }\left(r^{2}\right)\end{array}$ \\
\hline Arabinose & 0.3010 & -0.3816 & 0.9616 \\
Glucose & 0.6847 & -1.3536 & 0.9912 \\
Fructose & 0.3344 & -0.0018 & 0.9528 \\
Ribose & 0.6901 & -1.0372 & 0.9910 \\
Sucrose & 1.2694 & -2.4336 & 0.9988 \\
Lactose & 2.4877 & -6.3313 & 0.9991 \\
Raffinose & 3.5738 & -9.2108 & 0.9995 \\
Maltose & 2.1026 & -3.9428 & 0.9995 \\
\hline
\end{tabular}

drates are decreased with increasing temperature. The result indicates that the retention of strongly retained carbohydrates in anion-exchange chromatography is also an exothermic process (retention to be decreased with increasing temperature). That is the exchange reactions of strongly retained carbohydrates are also exothermic. However, the variation of retention time for each strongly retained carbohydrate is different with the change of temperature. Generally, the variation of retention time for tetrasaccharides is great than that for trisaccharides. Thus, selectivity changes of strongly retained carbohydrates can be achieved by changing the column temperature. Regression parameters of the Van't Hoff plots for four strongly retained carbohydrates are presented in Table 4. The slopes of the Van't Hoff

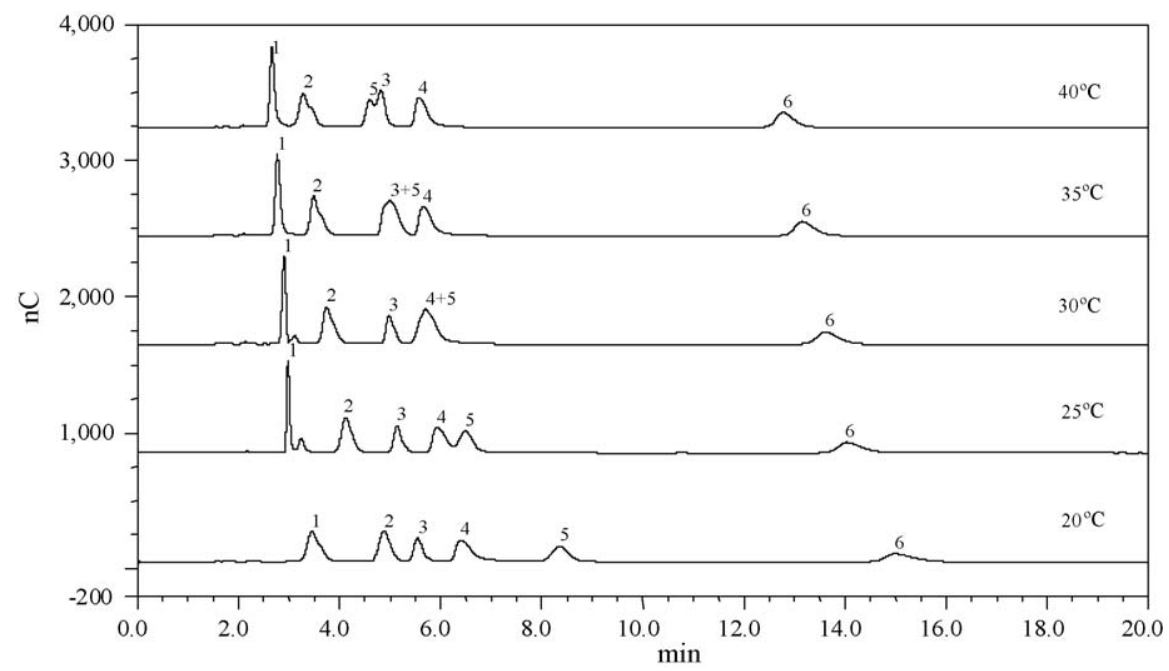

Fig. 5. Chromatograms of strongly retained amino acids and carbohydrates obtained with constant eluent concentration of $50 \mathrm{mM}$ sodium acetate and $60 \mathrm{mM}$ sodium hydroxide at various column temperatures from 20 to $40{ }^{\circ} \mathrm{C}$. Peak: (1) panose; (20) maltotriose; (3) glucuronic acid; (4) histidine; (5) maltotetraose and (6) phenylalanine. 


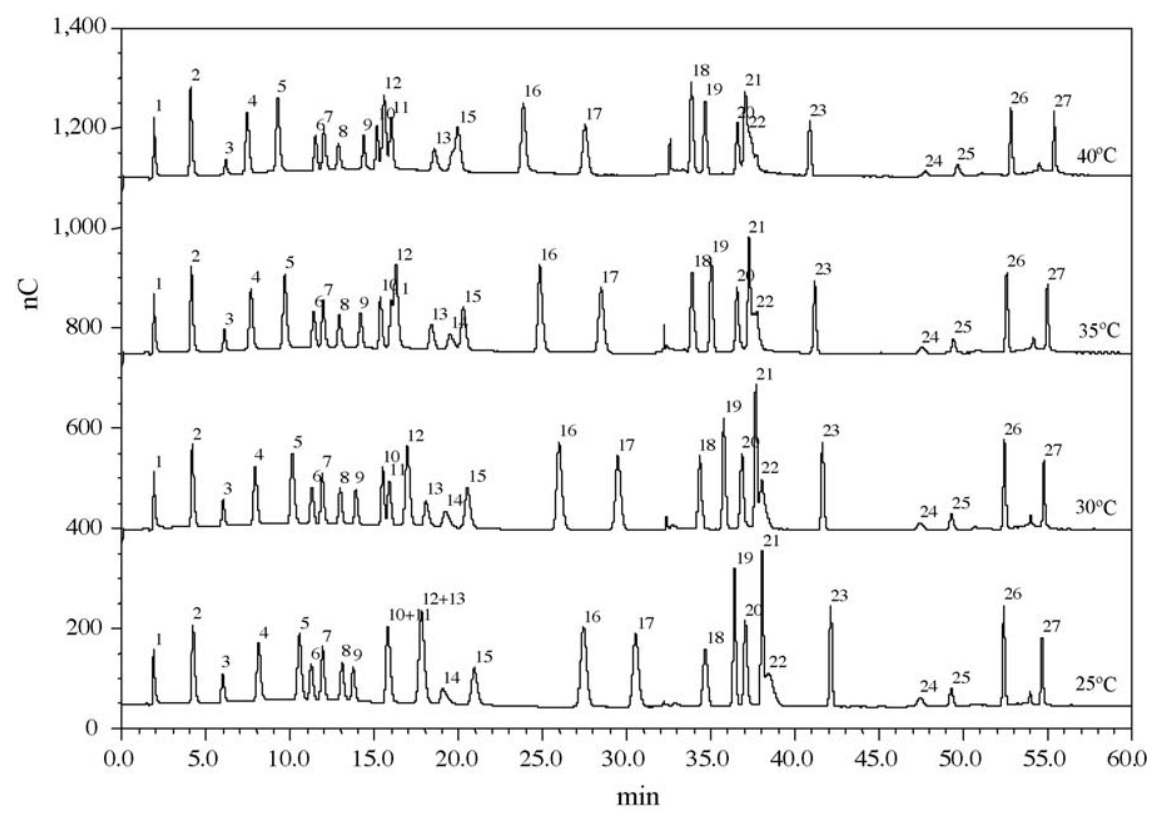

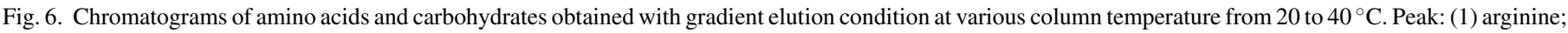

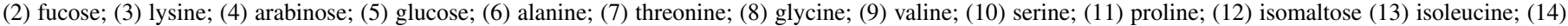

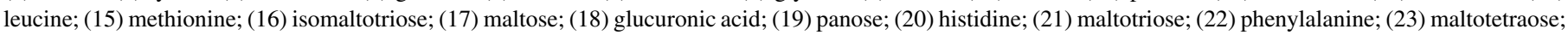
(24) glutamic acid; (25) aspartic acid; (26) cystine and (27) tyrosine.

plots are positive. The positive slopes indicate that the retention of strongly retained carbohydrates is an exothermic process. The separation between two closely eluted strongly retained carbohydrates can be improved by changing column temperature. For example, maltotetraose and glucuronic acid are the overlapping peak at 35 and $40^{\circ} \mathrm{C}$, but both are completely separated bellow $30{ }^{\circ} \mathrm{C}$.

\subsection{Effect of temperature on simultaneous separation of amino acids and carbohydrates}

The effects of temperature on amino acids and carbohydrates are discussed in the above sections, respectively. Because there are the difference between the effects of temperature on amino acids and carbohydrates, the separation of amino acids and carbohydrates can be improved by changing column temperature. Fig. 5 shows chromatograms of strongly retained amino acids and strongly retained carbohydrates obtained with constant eluent concentration of $50 \mathrm{mM}$ sodium acetate and $60 \mathrm{mM}$ sodium hydroxide at various column temperature from 20 to $40^{\circ} \mathrm{C}$. From the figure it is apparent that the separation of strongly retained amino acids and strongly retained carbohydrates can

Table 4

Linear regression data for plot of $\ln k^{\prime}$ vs. $1 / T\left(\times 10^{3} \mathrm{~K}^{-1}\right)$ of strongly retained carbohydrates with $50 \mathrm{mM}$ sodium acetate and $60 \mathrm{mM}$ sodium hydroxide eluent

\begin{tabular}{llcl}
\hline Analyte & Slope $=-\Delta H^{\circ} / R$ & $\begin{array}{c}\text { Intercept }= \\
\Delta S / R+\ln \phi\end{array}$ & $\begin{array}{l}\text { Correlation } \\
\text { coefficient }\left(r^{2}\right)\end{array}$ \\
\hline Panose & 2.3531 & -7.9353 & 0.9716 \\
Maltotriose & 2.8368 & -9.0026 & 0.9858 \\
Glucuronic acid & 0.8638 & -2.0700 & 0.9628 \\
Maltotetraose & 3.578 & -10.819 & 0.9833 \\
\hline
\end{tabular}

be improved by changing column temperature. Histidine and maltotetraose are the overlapping peak at $30^{\circ} \mathrm{C}$, maltotetraose and glucuronic acid are the overlapping peak at $35^{\circ} \mathrm{C}$, but three components are completely separated at $25^{\circ} \mathrm{C}$. This is because temperature was almost ineffective for strongly retained amino acids, and was marked different effect for strongly retained carbohydrates. Fig. 6 shows chromatograms of amino acids and carbohydrates obtained with gradient elution condition of

Table 5

Gradient condition for analyzing amino acids and carbohydrates

\begin{tabular}{llccc}
\hline Time (min) & Water (\%) & $250 \mathrm{mM} \mathrm{NaOH}(\%)$ & $1 \mathrm{M} \mathrm{NaAc}(\%)$ & Curve $^{\mathrm{a}}$ \\
\hline 0.0 & 93 & 7 & & \\
2.0 & 90 & 10 & & 5 \\
5.0 & 85 & 15 & & 8 \\
11.0 & 64 & 36 & & 8 \\
13.0 & 64 & 36 & & 8 \\
15.0 & 60 & 40 & & 8 \\
20.0 & 30 & 70 & 3 & 8 \\
25.0 & 30 & 70 & 7 & 8 \\
25.1 & 27 & 70 & 10 & 8 \\
33.0 & 23 & 70 & 20 & 8 \\
38.0 & 20 & 70 & 60 & 8 \\
45.0 & 10 & 70 & 60 & 8 \\
50.0 & 10 & 30 & & 5 \\
60.0 & 10 & 30 & & 5 \\
60.1 & 20 & 80 & & \\
63.1 & 20 & 80 & & 8 \\
63.2 & 93 & 7 & & 8 \\
90.0 & 93 & 7 & &
\end{tabular}

a Shapes of gradient curves are defined in the GS 50 Gradient Pump Operator's Manual, 37-38 (Dionex Document No. 031612, Revision 2). Curve 5 is linear while Curve 8 is one of the four available concave curves (6-9) with $20 \%$ of change at about $60 \%$ of a time segment and $70 \%$ change at about $90 \%$ of the same programmed time segment. 
Table 5 at various column temperature from 25 to $40{ }^{\circ} \mathrm{C}$. From the figure, we can see that under the optimal gradient eluent condition the separation of amino acids and carbohydrates can be improved by changing column temperature. For instance, isoleucine and isomaltose are the overlapping peak at $25^{\circ} \mathrm{C}$, isomaltose and proline are the overlapping peak at $35^{\circ} \mathrm{C}$, but the separation of isoleucine, isomaltose and proline is complete at $30{ }^{\circ} \mathrm{C}$. Therefore, for the simultaneous separation of amino acids and carbohydrates, in order to achieve the optimal separation, optimizing eluent condition and column temperature can be combined.

\section{References}

[1] D.C. Johnson, D. Dobberpuhl, R. Roberts, P. Vandeberg, J. Chromatogr. 640 (1993) 79.

[2] Y.C. Lee, J. Chromatogr. A 720 (1996) 137.

[3] T.R.I. Cataldi, D. Centonze, G. Margiotta, Anal. Chem. 69 (1997) 4842.

[4] A.P. Clarke, P. Jandik, R.D. Rocklin, Y. Liu, N. Avdalovic, Anal. Chem. 71 (1999) 2774.

[5] P. Jandik, A.P. Clarke, N. Avdalovic, D.C. Andersen, J. Cacia, J. Chromatogr. B 732 (1999) 193.

[6] H. Yu, Y.S. Ding, S.F. Mou, P. Jandik, J. Cheng, J. Chromatogr. A 966 (2002) 89.

[7] Y.S. Ding, H. Yu, S.F. Mou, J. Chromatogr. A 982 (2002) 237.

[8] L.A. Cole, J.G. Dorsey, Anal. Chem. 64 (1992) 1317.

[9] L.A. Cole, J.G. Dorsey, K.A. Dill, Anal. Chem. 64 (1992) 1324.

[10] M.C. Gennaro, D. Giacosa, C. Abrigo, E. Marengo, J. Chromatogr. Sci. 33 (1995) 360.

[11] P.L. Zhu, L.R. Snyder, J.W. Dolan, N.M. Djordjevic, D.W. Hill, L.C. Sander, T.J. Waeghe, J. Chromatogr. A 756 (1996) 21.
[12] J.W. Dolan, L.R. Snyder, N.M. Djordjevic, D.W. Hill, D.L. Saunders, L. Van-Heukelem, T.J. Waeghe, J. Chromatogr. A 803 (1998) 1.

[13] J.W. Dolan, L.R. Snyder, N.M. Djordjevic, D.W. Hill, T.J. Waeghe, J. Chromatogr. A 857 (1999) 1.

[14] J.W. Dolan, L.R. Snyder, N.M. Djordjevic, D.W. Hill, T.J. Waeghe, J. Chromatogr. A 857 (1999) 21.

[15] R.G. Wolcott, J.W. Dolan, L.R. Snyder, S.R. Bakalyar, M.A. Arnold, J.A. Nichols, J. Chromatogr. A 869 (2000) 211.

[16] H. Chen, Cs. Horváth, J. Chromatogr. A 788 (1997) 51.

[17] D. Bolliet, C.F. Poole, Analyst 123 (1998) 295.

[18] M.C. Pietrogrande, A. Benvenuti, F. Dondi, Chromatographia 51 (2000) 193.

[19] Y. Baba, N. Yoza, S. Ohashi, J. Chromatogr. 348 (1985) 27.

[20] Y. Baba, N. Yoza, S. Ohashi, J. Chromatogr. 350 (1985) 119.

[21] N.E. Fortier, J.S. Fritz, Talanta 34 (1987) 415.

[22] R.G. Smith, P.A. Drake, J.D. Lamb, J. Chromatogr. 546 (1991) 139.

[23] H.K. Lee, N.E. Hoffman, J. Chromatogr. Sci. 32 (1994) 97.

[24] E. Landberg, A. Lundblad, P. Pahlsson, J. Chromatogr. A 814 (1998) 97.

[25] M.G. Kolpachnikova, N.A. Penner, P.N. Nesterenko, J. Chromatogr. A 826 (1998) 15.

[26] M. Busch, A. Seubert, Anal. Chim. Acta 399 (1999) 223.

[27] C. Panagiotopoulos, R. Sempéré, R. Lafont, P. Kerhervé, J. Chromatogr. A 920 (2001) 13.

[28] P. Hatsis, C.A. Lucy, J. Chromatogr. A 920 (2001) 3.

[29] P. Hatsis, C.A. Lucy, Analyst 126 (2001) 2113.

[30] P. Hatsis, C.A. Lucy, Analyst 127 (2002) 451.

[31] P. Hatsis, C.A. Lucy, Anal. Chem. 75 (2003) 995.

[32] J. Chong, P. Hatsis, C.A. Lucy, J. Chromatogr. A 997 (2003) 161.

[33] L. Barron, P.N. Nesterenko, B. Paull, J. Chromatogr. A 1072 (2005) 207.

[34] H. Yu, Y.S. Ding, S.F. Mou, J. Chromatogr. A 997 (2003) 145. 